\title{
In defense of a fluctuating-interface, particle-accretion origin of folia
}

\author{
Donald G. Davis ${ }^{1}$
}

\begin{abstract}
:
Davis D.G. 2012. In defense of a fluctuating-interface, particle-accretion origin of folia. International Journal of Speleology, 41(2), 189-198. Tampa, FL (USA). ISSN 0392-6672. http://dx.doi.org/10.5038/1827-806X.41.2.6

Two recent papers have proposed radically different modes of origin for cave folia. Audra et al. (2009) propose subaqueous origin of carbonate folia via hypogenic $\mathrm{CO}_{2}$ bubble trapping, with concurrent condensation-corrosion and evaporative precipitation within individual folia gas pockets. Queen (2009) proposes that at least some folia are analogous to suboceanic tufa-tower "flanges" and may result from subaqueous freshwater mixing into a briny environment. The purpose of this paper is to show that neither of these mechanisms can be the fundamental process responsible for folia morphology in cave deposits, and that accretion from adherent particles at fluctuating interfaces is the only mechanism that has been shown to apply to folia of all compositions and in all cave environments where they are known to occur.
\end{abstract}

Keywords: folia; fluctuating interface; particle accretion; hypogenic speleogenesis; epigenic speleogenesis; brine mixing

Received 16 December 2011; Revised 18 February 2012; Accepted 3 March 2012

\section{INTRODUCTION}

Folia are relatively rare speleothems that manifest as fields of overlapping, downward-slanting, interleaved shelf-like structures that are best developed on overhanging cave walls. They are generally restricted to a limited vertical range in the host caves. They have most often been inferred to grow at or near the level of fluctuating water surfaces, but no definitive studies have been made to establish clearly their mechanism of development. Recently two new hypotheses have been put forth to explain folia, each radically different from the other: one invoking small-scale corrosion and calcite precipitation via $\mathrm{CO}_{2}$ degassing in hypogenic environments; the other invoking brine mixing. My intention here is to show that neither of these is a satisfactory alternative to a fluctuating-interface process based on particle accretion. My arguments will be based mainly on comparative field evidence, and I will not attempt to present a detailed descriptive model for folia development via accretion. However, I will try to show that the variety of folia compositions and environments eliminates the hypogenic and brine-mixing processes as feasible primary controls for folia deposition and morphology.

1441 S. Kearney St., Denver CO, USA (dgdavis@nyx.net)

\section{FOLIA AS AN INDICATOR OF HYPOGENIC DEGASSING (AUDRA ET AL).}

Focusing on observations in Adaouste Cave, France, Audra et al. (2009) postulate that folia can develop at depths as great as $30 \mathrm{~m}$ below the water surface, in active hypogenic conditions, by means of condensation-corrosion/redeposition processes in individual folia pockets acting as inverted dams for degassing $\mathrm{CO}_{2}$ bubbles. Elaborating on a concept first proposed by Green (1991), they conclude that:

"Folia, and moreover the association between folia and bubble trails, can be considered a very reliable record of hypogenic conditions. The hypothesis of an oscillating supersaturated water pool [cited as the concept of Davis, 1997] must be abandoned. First, because folia formed in this way should be widespread, when in fact they are extremely rare. Moreover, this hypothesis does not give a global explanation for the specific morphology of folia, such as inverted rims. Since degassing occurs at shallow depth below the water table, folia and bubble trails can also be considered a precise record of the water-table position, located at the top of the folia zone."

To clarify one of their statements above: Davis (1997) does not associate folia with pools. The Glossary of Geology (Jackson, 1997) defines "pool" as "a small, natural body of standing water...[including] a still body of water within a cave." 
Most cave pools are perched, with relatively stable levels controlled by spillovers. I regard perched pools as the environment of shelfstone, not folia. The folia environment, in my concept, is larger and more dynamic bodies of water - usually a climatically-controlled, variable-level interface where cave passages intersect the surface of a water table. I consider such cave/water-surface intersections as "windows" along whose margins folia may accrete - e.g., the Lake of the White Roses in Lechuguilla Cave, NM. More locally (specifically in Cuba), folia are known to occur in caves in the intertidal zone at sea level, and may rarely border ponded sections along streams where the ponding level is variable.

I contend here that folia are not reliably diagnostic of active hypogenic conditions, or even of former hypogenic environments (although the great majority of documented folia do occur in caves of hypogene origin, where intersecting water-table windows are most likely to be observable). Well-developed folia occur in at least one active cave (Hurricane Crawl, California) that both Audra et al. and I accept as epigenic in origin, and Odelsteinhöhle in Austria, also of clear epigenic origin (Plan \& De Waele, 2011). These cases in themselves invalidate folia as a reliable hypogenic indicator. Some of the shelves in Hurricane Crawl are very elongated horizontally, but with back-to-front slopes similar to typical folia - these features are convincingly intermediate between folia and shelfstone. In some places the Hurricane Crawl folia and folia/ shelves have the upper surfaces stained with settled sediment, which is consistent with development in an epigenic environment where sediment-bearing flooding sometimes occurs (Fig. 1).
I maintain instead that folia are indicative not of hypogene origin, but of the average level, at the time of folia growth, of a fluctuating surface bearing adherent particulate matter (assisted by chemical precipitation in some but not all cases) that attaches to the growing folia. Not only are folia fitting this origin not "extremely rare", this is the only case for which I have seen no contradictory examples. Further arguments to this effect follow.

\section{Carbonate folia: problems with rising gas bubbles as primary control}

\section{(1) Rarity of observed active bubble-trapping}

I have observed carbonate folia in the United States in Agua Caliente Cave, AZ; Bida Cave, AZ; Carlsbad Cavern, NM; Lechuguilla Cave, NM (two localities: Lake of the White Roses and Sulfur Shores); Indian Burial Cave, NV; Goshute Cave, NV; Hurricane Crawl Cave, CA; Crystal Sequoia Cave, CA (possible coarsely-crystalline folia); Groaning Cave, CO; and unnamed hydrothermal tubes near Glenwood Springs, CO. Of these cases, folia extend through active water levels in Lechuguilla Cave and Hurricane Crawl. In just one case - the epigenic Hurricane Crawl - have I seen a few bubbles slightly below the surface, that probably represented $\mathrm{CO}_{2}$ degassing.. Audra et al. (2009) state "we effectively observed such underwater process in grotta Giusti (Tuscany, Italy)," but do not give details. They infer that this occurred in Adaouste Cave, but did not confirm it by direct underwater observations.

The Lake of the White Roses folia site in Lechuguilla Cave has been dived, with the following observations reported (Hose, 1992):

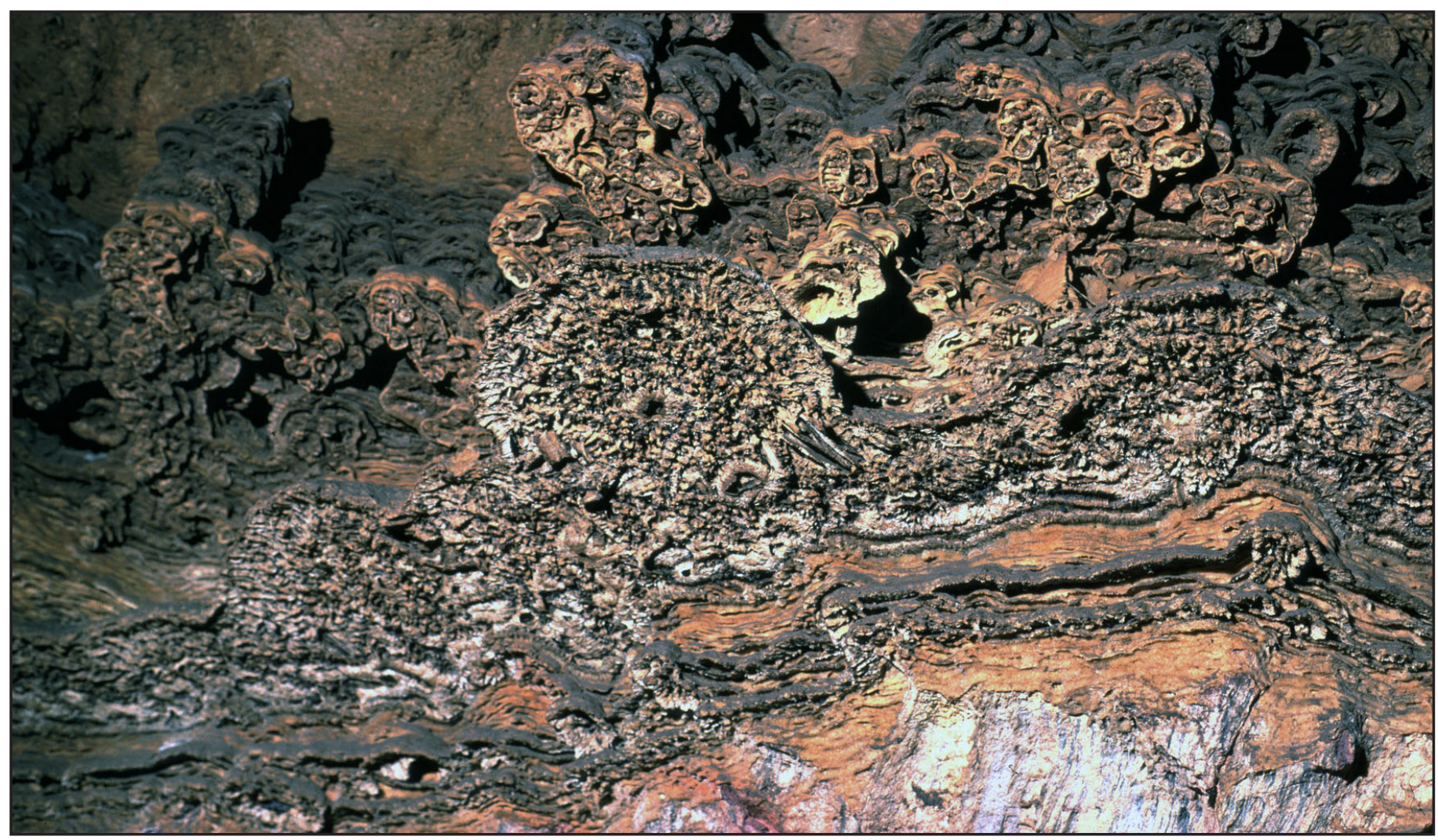

Fig. 1. Folia in Pumpkin Palace, Hurricane Crawl Cave, Kings Canyon National Park, California, USA. Note elongated shelfstone-like folia in lower right quadrant. The folia are in ponded zones along a stream passage; brown staining suggests settling of sediment introduced by epigene flooding (Photo by Joel Despain). 
“...The folia continue in a very similar style to shoreline deposits for about five feet below the present water surface. Between the five-foot and 30-foot level, the folia "peter out" in a manner similar to the change in the folia as one approaches the top of the rift. Below the 30-foot level, bedrock is exposed that is brown and very sharp pot marked with calcite rafts filling the hollows (potholes) all the way to the 92-foot level....the folia were also present in both of the air-filled domes but Bolt did not notice if the depth range was the same. No mammillaries were seen during the dive. Despite several checks, no air bubbles were seen trapped below the folia..."

\section{(2) Rarity of bubble trails and corroded folia in oth- er folia caves}

Association of bubble trails with folia in Adaouste Cave is a major argument used by Audra et al. (2009) to support their bubble-degassing hypothesis. However, I have not seen bubble trails in any of the folia sites I have visited (although they have been reported in the other European caves Pal-Volgy, Eremite, and la Baume - Philippe Audra, e-mail comm., February 2012). Audra et al. (2009) also report severe condensation-corrosion of the highest folia above the water level in the Adaouste site - another condition I have not seen at any other site.

\section{(3) Folia occurring where $\mathrm{CO}_{2}$ bubble trapping is not feasible}

There are several kinds of evidence suggesting that bubble trapping cannot explain the context and morphology of many folia:

(3a) If precipitation along the margins of underwater gas traps controlled the extension of the lower margin of folia shelves, the edges of these shelves should be as consistently horizontal as the gas/water interface. However, actual folia shelves undulate up and down significantly, with some extending noticeably below the limits of potential gas trapping within the pockets. In some places folia are also bimodal in size and shape, with isolated larger folia extending considerably below the general level. In this respect they differ from actual "inverted rimstone dams." Audra et al. recognize this, but do not explore the implications.

(3b) Folia do not, as Audra et al. (2009) state, grow "exclusively on overhanging walls", although overhanging walls are the most hospitable sites. The small folia in Groaning Cave, CO (Figs. 2A; 2B) (Davis, 1973) are on vertical to upward-facing walls.

In Lechuguilla Cave, some folia development occurs on vertical walls and even on somewhat upwardfacing surfaces. Simple geometry can explain why folia are not well developed on upward-facing surfaces. Where the angle of the bedrock slope approaches that of the downward slant of folia shelves, the slope of the folia must increasingly coincide with the slope of the substrate, leaving decreasing space for expression of the overlapping-shelf morphology.

(3c) Gas trapping cannot explain the inception of folia shelves. The initial stage of folia is preserved in many folia zones, at least near their upper and lower limits. These incipient folia are simple welt-like or
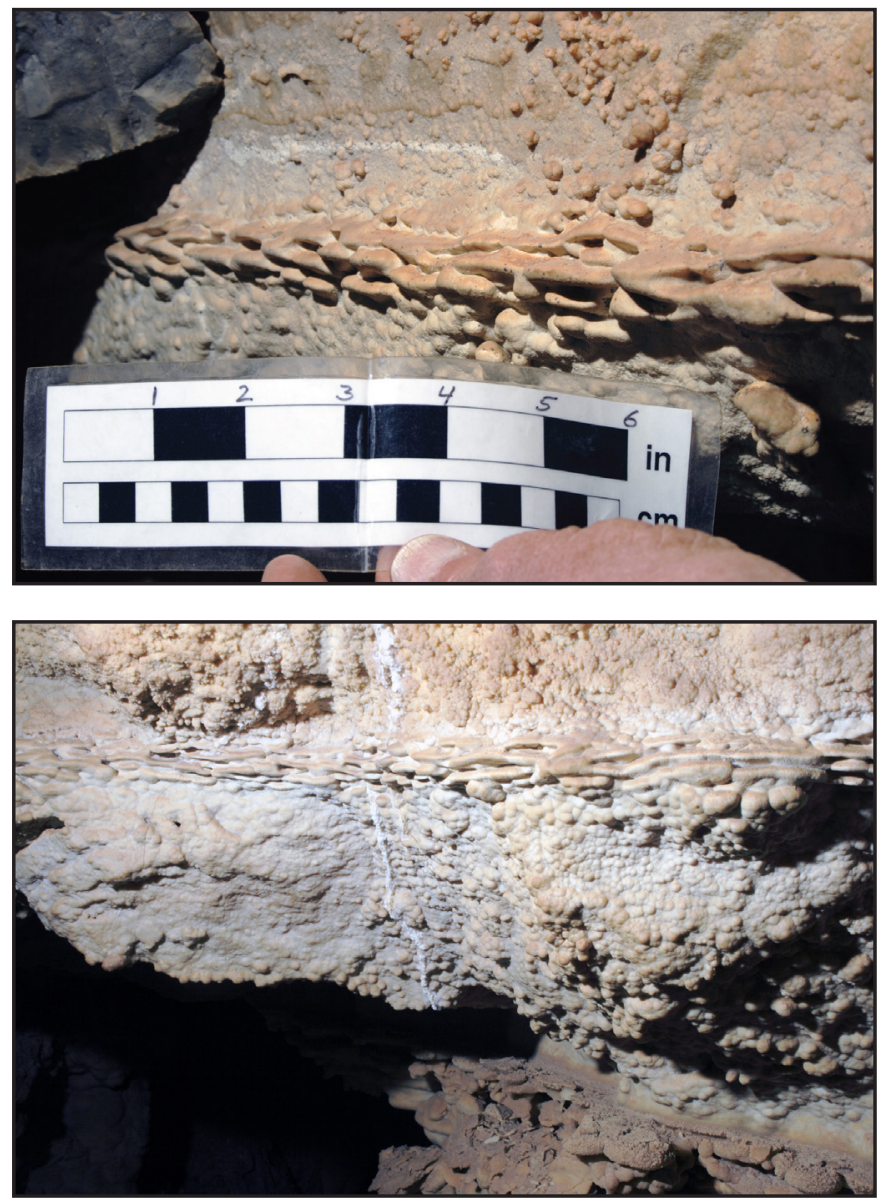

Fig. 2. (A) Folia in narrow horizontal band on vertical to upwardfacing wall in Cave, Colorado, USA. (B) Another view of folia band in Groaning Cave, with parallel shelfstone below (Photos by Norman Thompson).

knobby structures (e.g., Lyles, 2009; in El Malpais [a section of Lechuguilla Cave], "the cavers discovered rusticles coated with folia, a previously unknown combination.") Like those in Groaning Cave, these have no overhangs capable of trapping gas (Fig. 3). This is even more apparent in the case of vertical and upward-facing surfaces. Not until the outgrowths have extended out from the wall far enough to begin to show the characteristic overhanging morphology can it be possible for gas trapping on a significant scale to begin.

(3d) A subaqueous degassing model cannot account for the occurrence of very similar sloping-overhanging-shelf morphology in non-calcareous material, e.g., mud and sulfur. Audra et al., on the basis of their conclusion that folia are chemically precipitated via $\mathrm{CO}_{2}$ degassing, simply dismiss non-calcareous folia, which must be mechanically accreted, as a different phenomenon that should not be called folia. However, that is assuming the point to be proved. (Moreover, other accreted deposits having the morphology of similar chemically-deposited speleothems are recognized as a type of that speleothem; e.g., mud stalagmites). If accretion of suspended particles is in fact the primary process shaping folia, then I see no taxonomic reason why both carbonate and non-carbonate forms should not legitimately be called by the name folia. I discuss non-carbonate folia at greater length below. 


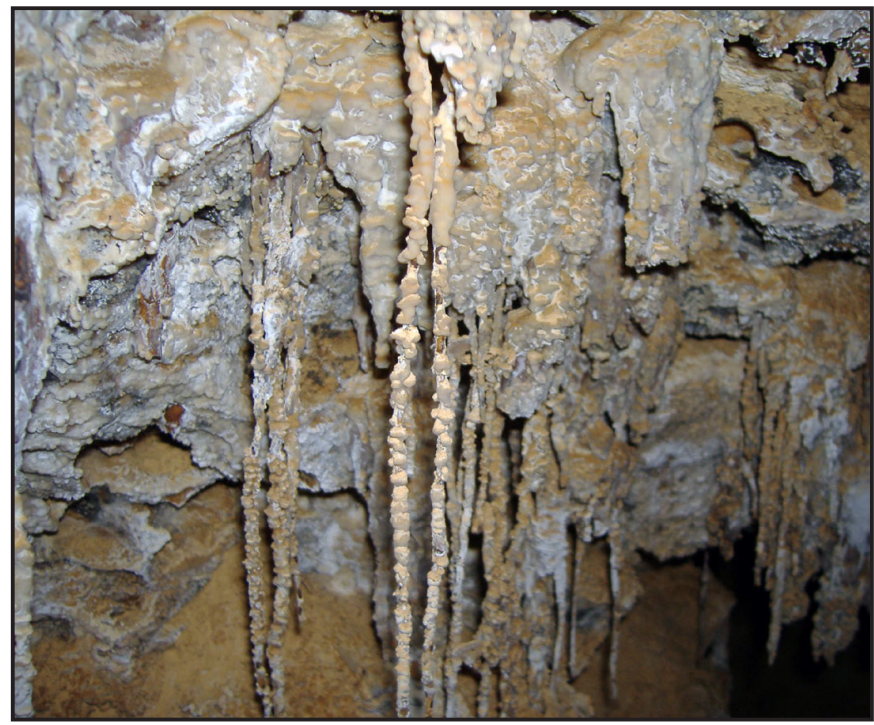

Fig. 3. Incipient folia encrusted on iron-mineral "rusticles" in the periphery of the folia zone near the Lake of the White Roses watertable window in Lechuguilla Cave, Carlsbad Caverns National Park, New Mexico, USA. The morphology is not adapted to gastrapping (Photo by Andy Armstrong).

Audra et al. (2009) describe a feature of Adaouste Cave that they name folia bubbles, which they explain as follows:

"We observed several calcite bubbles inside the folia hollows. We call these speleothems folia bubbles. They are composed of calcite that forms at the waterair contacts of bubbles, by centripetal growth. The development of such features needs the presence of a solution shifting to oversaturation at the water-bubble interface. We suggest the following origin ([Audra's] Fig. 6):

A film of condensation water appears at the vaulted solid top of the bubble, due to the thermal gradient between the thermal water and the rocky ceiling. The gradient is maintained by thermal flux through the rock;

In the high- $\mathrm{CO}_{2}$ atmosphere of the bubble, condensation water becomes hyper-aggressive;

The corrosive water dissolves the calcite and flows along the wall. This migration makes the solution progressively saturated;

At the base of the bubble, evaporation leads to supersaturation;

The calcite precipitates on the lower edge of the folia. The precipitation zone propagates along the bubble, at the water-bubble interface. Since this process involving calcite redistribution inside the cavity seems to be limited, calcite particle accretion from the degassing water-body may also participate to the building of the calcite bubble."

However, their Fig. 6 shows crystalline surface, like that on the surrounding walls, in the ceiling of the "folia bubble"; this does not seem to support condensation-corrosion having occurred there. Indeed, evidence of corrosion/evaporation cycles occurring in pockets on a scale of a few $\mathrm{cm}$ is lacking in any folia deposits that I have observed. Finally, I have found the same form of shelf-like rings around ceiling hollows, which rings I called "mud cavity collars", associated with mud folia in two western U.S. caves: Fort
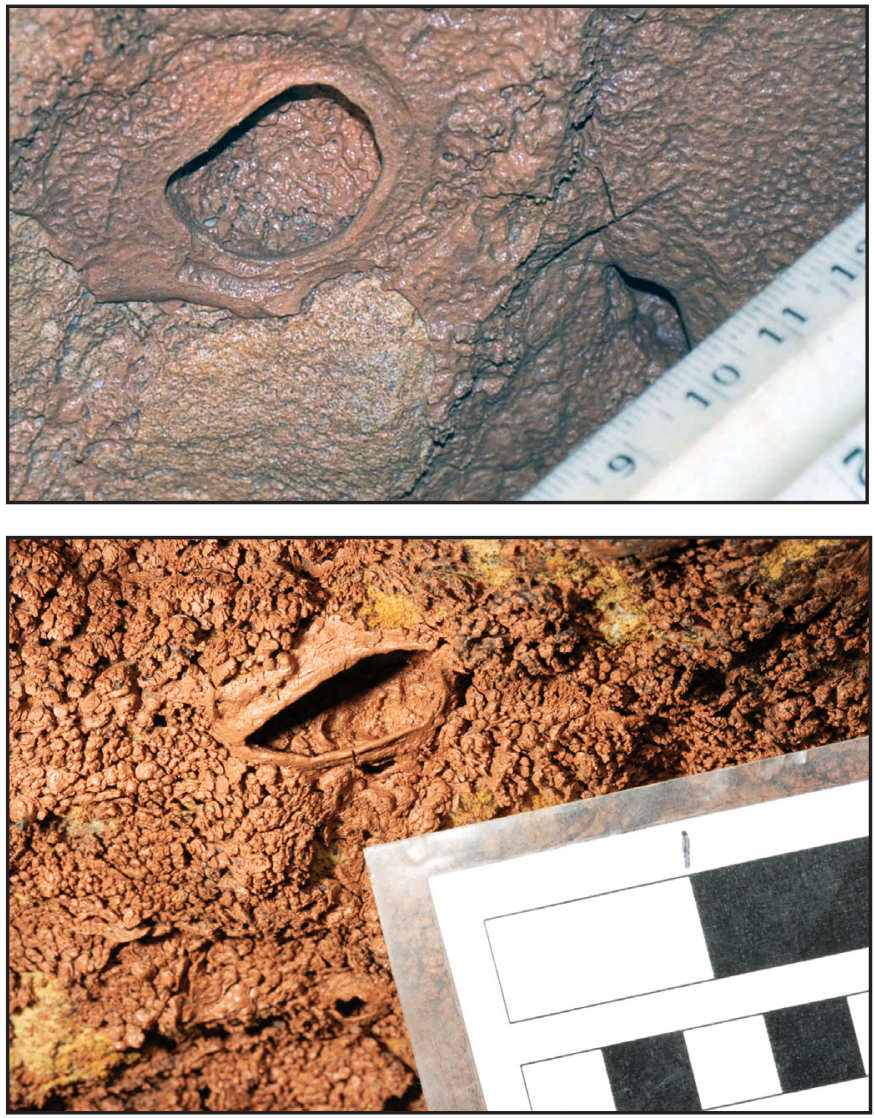

Fig. 4. (A) Mud cavity collar, associated with folia, in ceiling pocket of Main Corridor, Fort Stanton Cave, New Mexico, USA (Photo by Bob Pape). (B) Mud cavity collar in Heavenly Hall, Cave of the Winds system, Colorado, USA (Photo by Norman Thompson). These are mud homologues of the calcite "folia bubbles" shown in Fig. 6 of Audra et al. (2009).

Stanton Cave, NM (Fig. 4A) and Cave of the Winds, CO (Fig. 4B). Such mud rings obviously cannot be created by oversaturation resulting from $\mathrm{CO}_{2}$ chemistry, nor can they be evidence for thermal or hypogenic processes. The horizontal rings that demarcate "folia bubbles" in Adaouste Cave, like mud rings in mudfolia sites, can be interpreted as simply folia material that accreted along a flatter angle because trapped air prevented water from rising farther into the pocket when the water table rose past that level.

\section{Carbonate folia: internal structure}

Fig. 5 is a cross-section through a typical group of folia from Indian Burial Cave, Nevada. The first speleothem deposit over bedrock is subaqueous mammillary crust. At the phreatic-crust/folia-base demarcation there is an abrupt change in texture, which I interpret as marking the time when entirely-subaqueous mammillary-coating deposition was superseded by the folia regime that was active during fluctuations of the water-table surface through the zone of folia growth. Growth lines in the folia indicate more calcite accumulation on the upward- and outward-facing surfaces of the folia shelves than on the undersides. However, there is no sign of corrosion on the undersides where $\mathrm{CO}_{2}$ might have been expected to be trapped if the folia environment of Audra et al. had been in effect. These observations are consistent with the Davis accretion concept. 


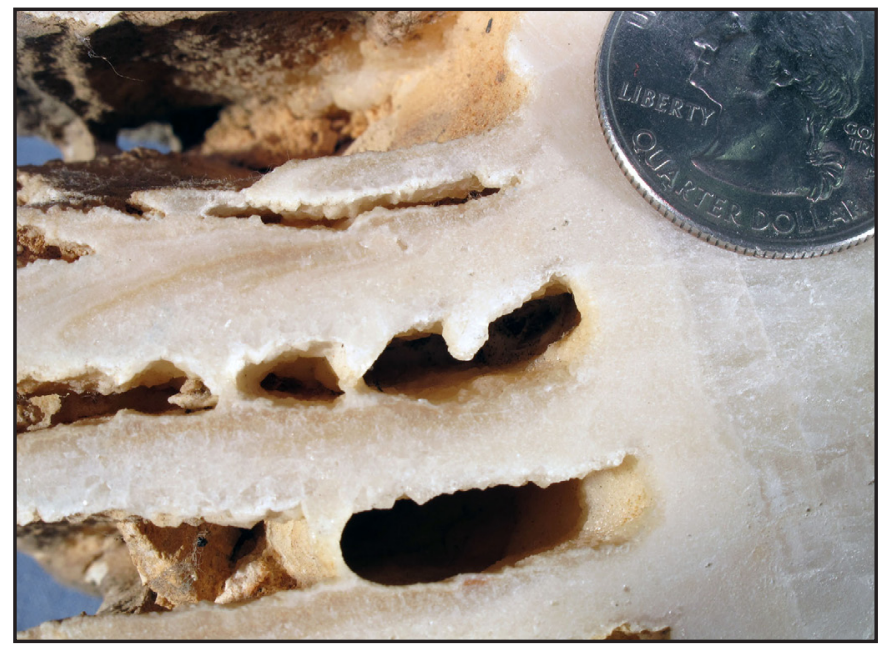

Fig. 5. Indian Burial Cave, Nevada, USA folia, showing distinct demarcation of folia from underlying mammillary crust, and internal growth lines. Growth was preferential in the upward and outward directions, with no evidence of corrosion on the undersides (Photo by Peter and Ann Bosted).

\section{Non-carbonate folia}

Concerning non-carbonate folia, Audra et al. (2009) conclude:

"Folia cover large areas and have unambiguous morphology. Consequently, their occurrence seems to be almost exclusively correlated to a carbonic acid, hypogenic context, involving degassing at shallow depth below the water table. Similar features that occur in non-hypogenic context (e.g., in halite or clay) are clearly different, from both a morphological and a genetic point of view. Their inclusion in the term "folia" should be abandoned."

I contend that Audra et al. (2009) have not well supported their claim that carbonate folia are "almost exclusively" products of hypogenic bubble degassing. In addition, I judge that non-carbonate folia should be retained within the folia category; some supporting arguments follow.

\section{Mud folia}

Audra et al. (2009) assert:

"Some features resembling folia are made of minerals other than calcite:... However, their morphology differs significantly: rims do not overlap and do not form individual inverted cusps. Since they are much too soft to be generated by oscillating water, these clay rims are apparently produced by the regular lowering of a turbid water body (Green, 1997)."

In the Cave of the Winds, CO mud-folia site (the Snider Extension, Davis 1982), the mud folia shelves, though relatively longer and less interweaving than typical calcite folia, do in some cases overlap in such a way that hollows beneath them would be capable of trapping air when the water rose (Fig. 6).

Mud folia, like calcite folia, are bimodal in shape. The gently-sloping, tiered type is closer in shape to most calcite folia. The second type is isolated, more steeply-inclined, thin curtains of mud, with approximately-horizontal lower edges, that bridge spaces between ceiling points. (The extended-fringe form of calcite folia does not typically bridge gaps in this way). Both the tiered and curtain (Fig. 7) types occur in Cave of the Winds. In Fort Stanton Cave, NM, only the curtain type is widespread (Davis, 2010) (Fig. 8), although a horizontal, downwardly-sloping mud shelf (morphologically resembling the intermediate folia/ shelfstone of Hurricane Crawl Cave) has also been recorded (Fig. 9). The curtain type does not often form potentially air-trapping pockets. Both caves have almost identical versions of the "mud cavity collars" that closely resemble in shape and size the calcite "folia bubbles" of Audra et al.

I do not see why these features should be "much too soft to be generated by oscillating water", provided that the oscillations were slow, low-energy rises and falls of turbid water whose surface was coated with a sticky scum of mud that would accrete to walls, in the same way as I postulate that a calcite scum does in creating carbonate folia.

\section{Sulfur folia}

Hose (2009) describes remarkable, actively-growing folia composed of elemental sulfur in Cueva de Villa Luz, Mexico. They are small (no more than a few $\mathrm{cm}$ across), are not as laterally extensive as most other types of folia deposits, and most of them are relatively flat-bottomed, with masses of sulfur filling in much of the volume that would be inverted cups in other folia. However, they do form overlapping, sloping-topped shelves that are easily recognizable as very similar to folia morphology in other materials (Fig. 10).

Hose states that "The sulfur folia are clearly subaerial deposits.... The massive sulfur deposits grow on
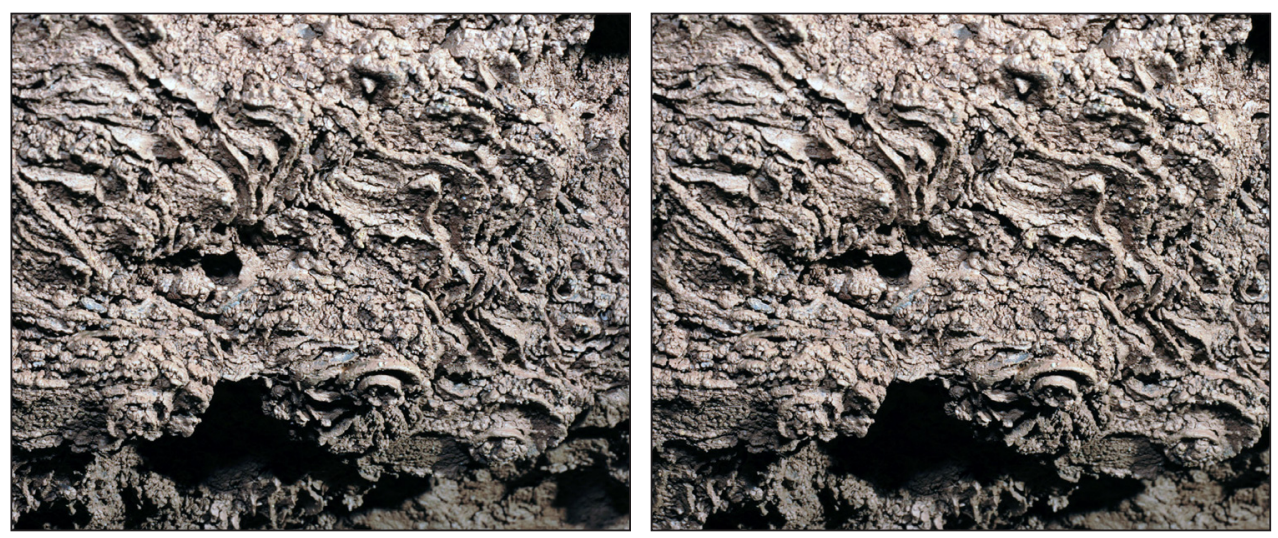

To view this stereo pair without a stereo viewer: with your eyes close to the figure, look at a prominent feature in the images; then allow your eyes to relax so that the paired images converge toward the center; they should merge into a single 3-D image.

Fig. 6. Field of mud folia on ceiling in Snider Extension, Cave of the Winds system, Colorado, USA, looking diagonally upward toward the ceiling: stereo pair (Photos by Norman Thompson). 


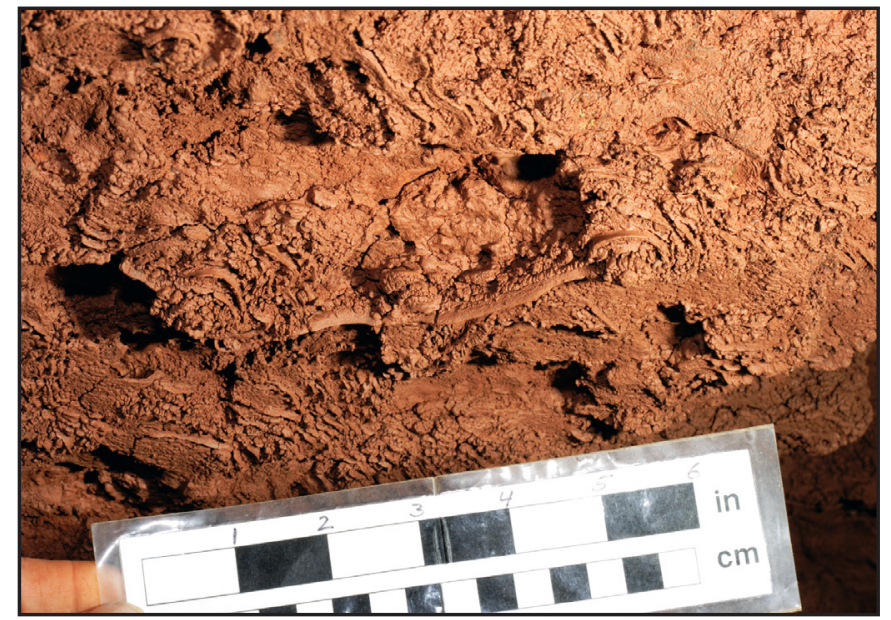

Fig. 7. Folia on ceiling in Snider Extension, Cave of the Winds system, Colorado, USA; curtain-type folium in center (Photo by Norman Thompson).

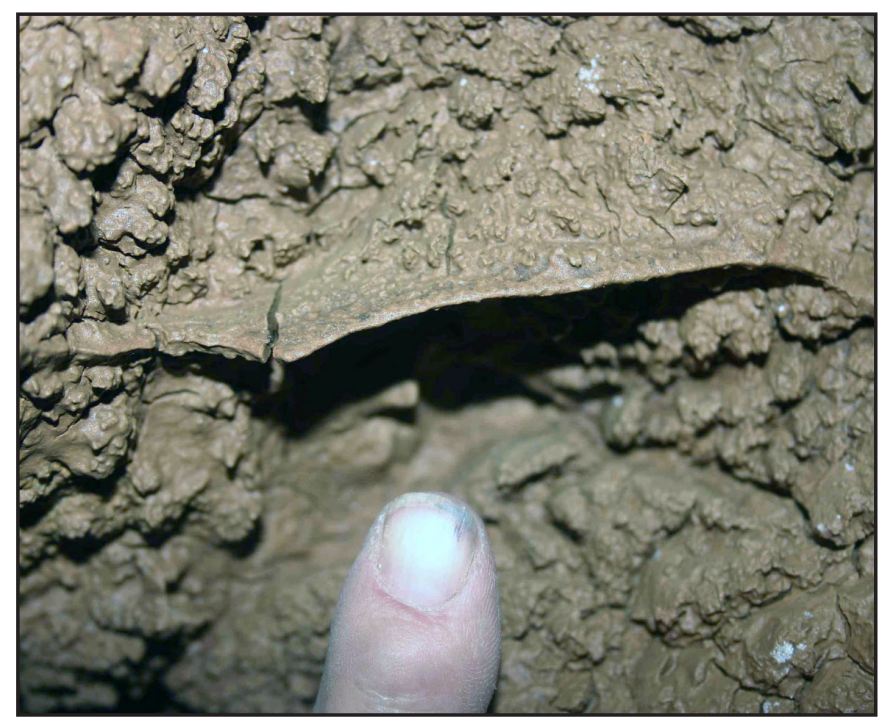

Fig. 8. Isolated curtain-type folium in Main Corridor, Fort Stanton Cave, New Mexico, USA (Photo by Wayne Walker).

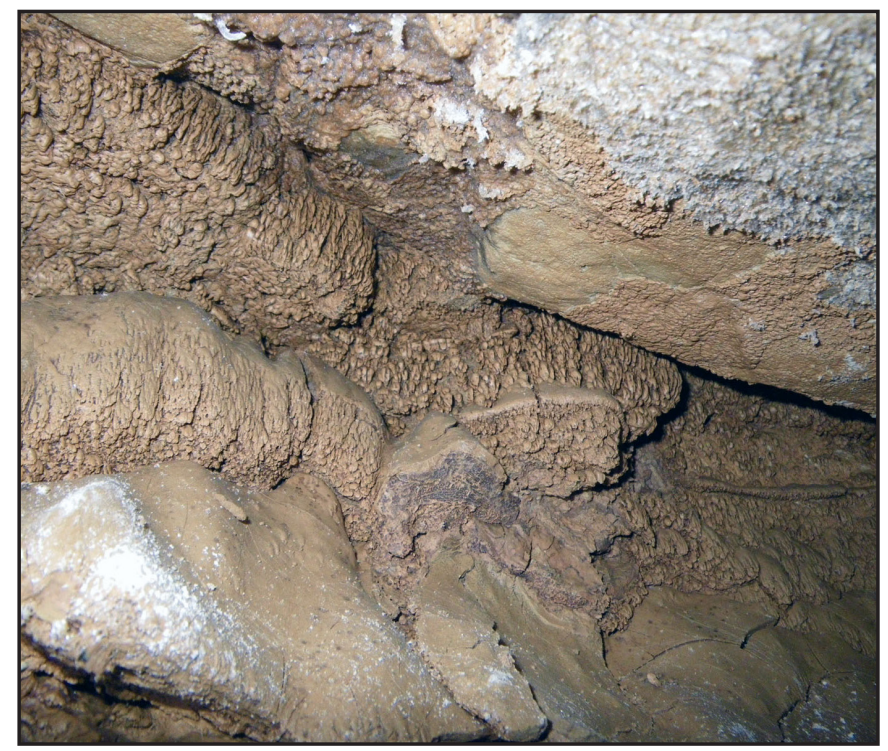

Fig. 9. Mud accretions in southern branch of Fort Stanton Cave, New Mexico, USA: note horizontal structure, with sloping upper surface, resembling shelfstone and folia (Photo by Pete Lindsley). selenite crystals, which ubiquitously coat the walls in this area. Some of the folia engulf the selenite..." The folia deposits extend higher than the water of the sulfidic springs below them ever rises, and their subaerial origin was conclusively demonstrated by the accidental breakage of a patch of them in 1999, followed by regrowth of a new folia coating by ten years later. Hose interprets their genesis as follows:

“...This relatively confined area also consistently contains the highest concentration of atmospheric hydrogen sulfide $\left(\mathrm{H}_{2} \mathrm{~S}\right)$, which has rarely been measured at less than 50 ppm and commonly exceeds 70-100 ppm when visitors are present. These observations lead to the hypothesis that the warmer, sulfidic air rises from above the sulfidic inlet (Lake of the Yellow Roses), mixes with the higher and slightly cooler, oxygenated air that circulates into the area from the surface, resulting in the subaerial precipitation of sulfur crystals. The sulfur may precipitate directly on the surface of selenite crystals on the walls or in the air, then drift down onto the walls to form the distinctive folia form."

These sulfur folia do depend on hypogenic degassing, but the gas is $\mathrm{H}_{2} \mathrm{~S}$ and the environment is not subaqueous, leading Audra et al. to deny that they are true folia. I accept them as folia on the basis that, like carbonate and mud folia, they are associated with a fluctuating interface that generates adherent particles. Here, the interface is not water/air: it is a layer of sulfidic air along the floor (rising and falling in response to episodic belches of $\mathrm{H}_{2} \mathrm{~S}$ from the sulfidic

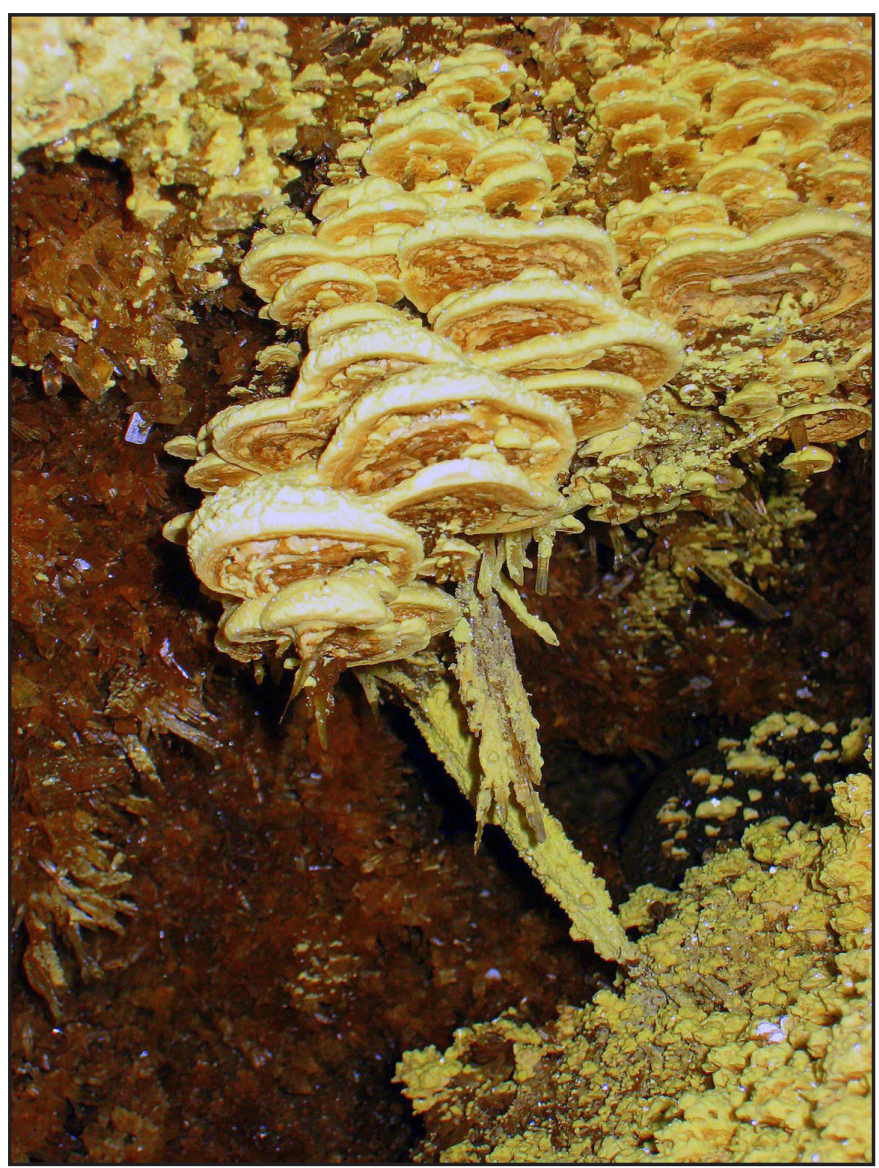

Fig. 10. Sulfur and sulfur folia on gypsum crystals, Cueva de Villa Luz, Tabasco, Mexico (Photo by Louise Hose). 
springs in the stream), with oxygenated air above. This forms what I will call an "atmospheric sulfocline" along which, presumably, most of the fine sulfur particles that accrete to form the folia are generated by $\mathrm{H}_{2} \mathrm{~S}$ oxidation. Thus these sulfur features share with carbonate and mud folia the diagnostic property of association with a rising and falling interface between differing media. ${ }^{1}$

\section{FOLIA AS A SUBAQUEOUS BRINE-MIXING DEPOSIT (QUEEN)}

Queen (2009) presents a radical new hypothesis proposing that at least some folia may develop at indefinite depth in a brine-bearing phreatic zone where fresh water seeping from porous cave walls rises, because of the density gradient, along overhanging surfaces, interacting with the brine where temperature and $\mathrm{pH}$ are such as to cause carbonates to precipitate in folia structures at the brine/freshwater interface. His primary inspiration is the recentlydiscovered "Lost City" field of tufa towers on the seabed of the Mid-Atlantic Ridge, where inverted-dam flanges form where rising thermal water leaks from the sides of the towers. He states that "These flanges are considered to be analogues of folia and suggest an alternative mode of formation for these rare cave features". Unlike Audra et al., he does not assert that all genuine folia must fit his new model and that previous models for folia growth must be abandoned. But he believes that a mixing model explains some folia traits not addressed by earlier ideas, and writes:

"Models for folia growth that suggest they are the equivalent of gours forming at the water surface on vertical or overhung surfaces fail to explain why no comparable features are developed on upward-facing surfaces, nor why they are not equally developed on all overhanging surfaces within a particular area."

However, these particular points are easily dealt with in the Davis model. As I pointed out in considering the Audra et al. hypothesis, it is simply not correct that folia never occur on upward-facing surfaces. They sometimes do, but become increasingly subdued as the slope of the surfaces approaches that of the folia, rendering the expression of foliastructure geometrically infeasible. Encrustations contemporaneous with adjacent folia deposits may be continuous from the folia displays down across upward-facing surfaces below; only the folia pattern progressively disappears downward.

It is true that in some folia sites (e.g., the chamber below the Christmas Tree Room in Carlsbad Cavern), folia are not equally distributed on all overhangs at the same level around the chamber. However, there is no need to invoke freshwater seeping into ambient brine from localized permeable places to account for this. In a model assuming folia accretion from carbonate scum on the water surface, air currents above the water (and fluid currents within it) may drive scum and raft fragments preferentially toward certain places in the chamber, resulting in unequal growth of folia accreting from this floating matter. I have seen such directional raft accumulation on the water surface at the Lake of the White Roses folia site in Lechuguilla Cave.

In Hurricane Crawl, CA, where folia occur along ponded segments of an epigenic stream, a different control on folia distribution is seen. Folia are best developed where the water rises from sumps along the streamcourse, presumably because degassing from the water surface is interrupted in the sumped segments. As the water re-encounters air, calcite precipitates out via degassing, and folia development is progressively more attenuated downstream from the points where upwelling occurs.

Queen notes, as I have, that in some locations carbonate folia are bimodal in size and shape. The most common kind, forming fields of sloping, tiered shelves, he calls Type I. Folia of a less common form, larger and more isolated, flare outward farther, and have "a lower surface that may be inclined from one side to the other" - these he calls Type II. (In my experience, the lower margins of Type II folia do not always slope to one side, but may curve convexly across the middle). Queen suggests that "differences between Type I and Type II folia might result from the site-specific supply rate of water seeping though the porous wall, with greater supply rates or smaller differences in fluid density being associated with inclined fresh water-brine interfaces."

However, directional current-driven drift of watersurface scum can equally well explain the properties of Type II folia. Where the scum is most concentrated, it is likely to stay in contact with the folia margins longer when the water level drops, leading these most favored folia to grow downward farther than average, and giving rise to the uneven Type II margin slopes as portions of the edge progressively lose contact with the water.

Queen represents the Davis model as follows:

"Davis $(2000,2004)$ has proposed that folia result from evaporation and degassing at the water-rock contact at the top of pools in flooded caves, broadly comparable to microgours forming from water flowing over inclined surfaces, and with the trapping of suspended material. He compares the vent and flange deposits at the Lost City to tufa deposits at Mono Lake, California, which also form from mixing. Davis generally minimizes the similarities of folia with vent flanges. Although he accepts a mixing origin for both folia and helictite bushes, he ascribes them to different processes."

As with Audra et al. (2009), the allusion to "pools" mischaracterizes the Davis concept.

In past writings, I have used "inverted rimstone dams" as a broadly descriptive analogy to folia morphology, but I regard tufa-tower flanges as inverted rimstone dams in a far more literal sense. At both Mono Lake and the Lost City, flanges bulge sharply outward from isolated leak points on tower walls

${ }^{1}$ Halite folia: another type of non-carbonate folia, halite folia, has been reported from Liquid Crystal Cave, Israel, a vadose cave in a halite host matrix (Frumkin, 1997). However, Frumkin has subsequently re-interpreted these deposits as shelfstone (Audra et al. 2009; Frumkin, e-mail comm., February 2011). I know of no published report of halite folia from any other site, though their existence should be consistent with my folia concept. 
(Fig. 11), and do not form contoured tiers of interweaving shelves. They are much larger than is typical of folia; they often bulge outward beyond the rims of the trap-hollows, which are smaller in relation to their wall thickness than in folia. In active flanges, the shimmer of trapped thermal water can actually be seen in images taken from deep-sea vehicles, spilling upward across margins that are more distinctly horizontal than those of folia. It seems clear that for tufatower flanges, inverted rimstone dams are by far the closest homologues in both morphology and process; folia are much less similar.

I am not sure what Queen means by "although [Davis] accepts a mixing origin for both folia and helictite bushes, he ascribes them to different processes." I do not know of any folia that I thought required a mixing origin (unless "mixing" is taken to include $\mathrm{H}_{2} \mathrm{~S}$ / $\mathrm{O}_{2}$, in the case of sulfur folia). The helictite bushes which Queen notes that I have interpreted as subaqueous (Davis, 1989, 1991) are the unique upwardgrowing clusters of hollow tubes in Wind Cave, SD (not to be confused with the subaqueous helictites of Lechuguilla Cave, which have very different morphology and context). I do agree that a subwater-table

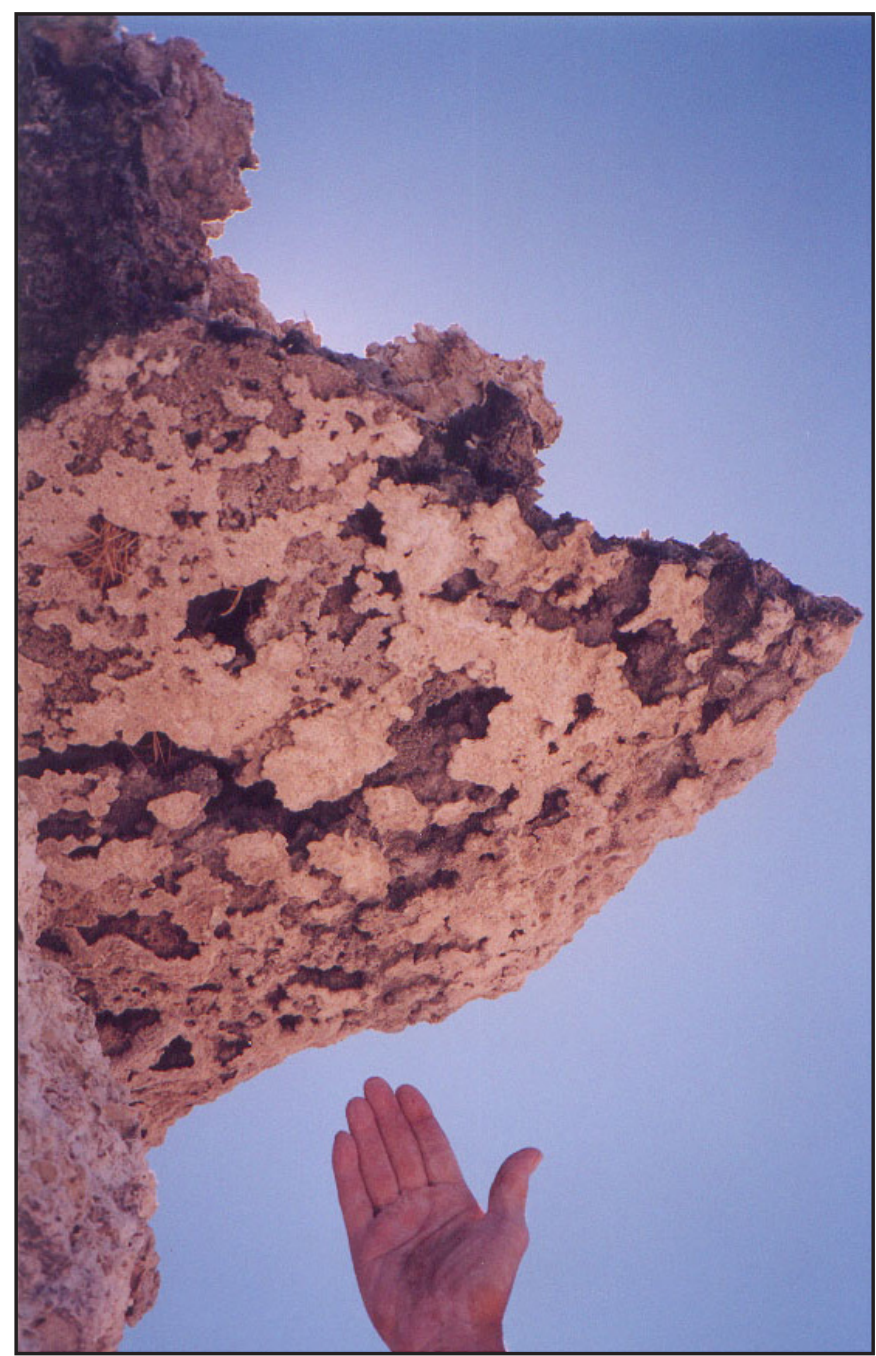

Fig. 11. Tufa-tower flange, Mono Lake, California, USA: considered here as an inverted rimstone dam complex in which the hollows on the underside originally held less-dense fluid surrounded by denser fluid (Photo by Andy and Bonny Armstrong). mixing model for the Wind Cave bushes is indicated, and have suggested that they are differently-shaped, low-energy homologues of the Mono Lake and Lost City tufa towers. The Wind Cave helictite bushes, however, have interweaving strap-like morphology quite unlike the Carlsbad Cavern branching-acicular aragonite trees that Queen thinks - as with the nearby folia in Carlsbad Cavern - may be of subaqueous mixing origin. Furthermore, if the Wind Cave bushes represented the results of mixing at upward-facing surfaces as per Queen's model, it would follow that overhanging surfaces in the same areas should show mixing-origin folia deposits where mixing water entered from behind those surfaces. But they do not; folia are entirely absent from any reported locality in Wind Cave.

It is not particularly clear whether Queen considers any known deposits of folia to be examples of his mixing mechanism, although he appears to regard the Carlsbad Cavern folia as consistent with it. It seems to me, however, that in addition to the issues raised above, Carlsbad and other hypogenic caves in continental interiors have a problem with the timing of events. Brines, where they occur at all during the life cycle of continental hypogenic caves, are usually present during the dissolution phase, and have been flushed from the rock by the time the voids reach maximum size and begin to develop folia and other secondary encrustations (as in Carlsbad and Lechuguilla). Furthermore, I know of no reported carbonate folia that are not associated with calcite rafts, which suggests that the folia did not form at significant depth below the water table.

I believe that Queen has offered a conceptually interesting idea, against which new discoveries of folia should be evaluated, but that he has not presented convincing evidence that his brine-mixing model is responsible for any presently-known examples of cave folia. I do agree with him that marine-vent and cave phenomena share processes that can contribute to understanding of both realms.

\section{DISCUSSION}

To make a stronger case for the Audra et al. (2009) bubble-degassing model for folia development, the best contextual evidence would be observing folia in an active bubble-degassing site deeper in the water than there is any evidence that the water surface has ever descended, with trapped-gas pockets visible, and with calcite rafts absent at that level. Such a demonstration would require either scuba (preferably rebreather) gear, or extending a camera lens on a probe deep enough below the water surface.

Likewise, the best contextual support for the Queen vent-mixing model would be discovery of an active folia site in a brine/freshwater-mixing environment, with calcite rafts absent. A prime area for investigation would be Cuba, where large-scale folia deposits have been reported in partly-flooded caves near sea level and having haloclines within the water (Kevin Downey, e-mail comm., 27 September 2010). Photographs of such a site have been posted on a 
website by Hall (2008), who captioned these folia as "formed at the interface of fresh and saltwater," without, however, explaining why she made this interpretation. Audra et al. (2009), in citing Hall, did not mention this statement but referred to the site as one in which "the air is mechanically trapped by tidal fluctuations," and is therefore an exception to their degassing model. In inactive sites, a proxy for direct observation of brine would be identification of saline fluid inclusions in the deposits.

\section{CONCLUSIONS}

Regarding the proposal of Audra (2009): whether or not it is correct for their Adaouste Cave case, subaqueous $\mathrm{CO}_{2}$-bubble degassing on a scale that would trap gas in folia pockets should enhance folia development, by increasing precipitation along the margins while preventing it in the gas-filled pocket. However, bubble-forming degassing can apply to only a limited subset of folia compositions and environments, so although it can assist folia growth in degassing environments, it cannot be required for folia inception, or be the primary factor in the determination of folia morphology.

Regarding the concept of Queen (2009): development of folia or folia-like features via brine/freshwater mixing is an idea worth bearing in mind for plausible environments, but lacks persuasive empirical support to date. I conclude that, in the absence of stronger evidence than the above authors have yet presented, folia development via particle accretion at a fluctuating water level (or, in the case of the sulfur folia of Cueva de Villa Luz, a sulfidic/oxygenated atmospheric interface) remains the best-supported mechanism.

Understanding the taxonomy and growth of folia are of interest in themselves, but establishing correctly the zone of folia development also has broader implications, because folia are being used by paleoecologists and paleoclimatologists (e.g., Szabo et al., 1994) to determine past water-table levels, and incorrect assumptions about the nature and environment of folia may skew conclusions in these fields.

If, as I propose, accretion at a fluctuating water level is the chief determinant of folia growth (that level representing, in most but not all carbonate-folia cases, the water table), then an individual folia shelf represents approximately the limited vertical range of the varying water level at the time each shelf is accreting - growing intermittently along the top of the flooded zone, and accumulating most of its material while in a rising and falling interface range of as little as a few $\mathrm{cm}$ or less at one time. However, if the subaqueous- $\mathrm{CO}_{2}$-degassing or brine-mixing interpretations were valid, entire fields of folia could grow simultaneously underwater across greater vertical range; thus the folia could deposit across much more extensive depth (extending tens of meters or more) beneath the water surface at the same time, and would be less sensitive indicators for the time when that water surface existed.

\section{ACKNOWLEDGEMENTS}

My thanks to Norman Thompson for high-quality photographs of folia sites not previously photodocumented, and to Arthur and Margaret Palmer for reading the manuscript and assistance in photo preparation.

\section{REFERENCES}

Audra P., Mocochain L., Bigot J.-Y. \& Nobécourt J.-C., 2009 - The association between bubble trails and folia: a morphological and sedimentary indicator of hypogenic speleogenesis by degassing, example from Adaouste Cave (Provence, France). International Journal of Speleology, 38: 93-102.

Davis D.G., 1973 - Miniature folia in Groaning Cave, Colorado. Caving in the Rockies. Colorado Grotto, National Speleological Society, 15: 1.

Davis D.G., 1989 - Helictite bushes - a subaqueous speleothem? National Speleological Society Bulletin, 51: 120-124.

Davis D.G., 1990 - By deepest Lechuguilla's waters. Rocky Mountain Caving (Colorado chapters, National Speleological Society), 7: 26-27.

Davis D.G., 1991 - Wind Cave helictite bushes as a subaqueous speleothem: further observations. $\mathrm{Geo}^{2}$ (Geology and Geography Section, National Speleological Society), 19: 13-15.

Davis D.G., 1997 - Folia in Hurricane Crawl Cave and Crystal Sequoia Cave. San Francisco Bay Chapter Newsletter (National Speleological Society), 40 (5): http://www.caves.org/grotto/sfbc/news/vol40/ issue-40-5.html

Davis D.G., 2004 - Helictite bushes, tufa towers, and inverted rimstone dams. Geo ${ }^{2}$ (Geology and Geography Section, National Speleological Society), 31: 13-19.

Davis D.G., 2010 - Some highlights of the fall 2009 Fort Stanton expedition. Rocky Mountain Caving (Colorado chapters, National Speleological Society), 27: 16-20.

Frumkin A., 1997 - Liquid Crystal Cave, Israel. In: Hill C. \& Forti, P. (Eds)., Cave minerals of the world, 2nd ed. Huntsville, AL, USA: National Speleological Society: 319-322.

Green D. J., 1997 - The origin of folia. Salt Lake Grotto Tech. Note, 96: 51-60 [abstract in Journal of Cave and Karst Studies, 59 (1): 60].

Hall L. 2008 - Cuban Caves Photo Page, El Jarrito Bellamar Cave system, Matanzas province, Cuba. The Pittsburgh Grotto, National Speleological Society: http://www.karst.org/pgrotto/cubapics.htm

Hose L., 1992 - To Lechuguillan depths. Rocky Mountain Caving (Colorado chapters, National Speleological Society), 9 (2): 15-18.

Hose L., 2009 - Recent observations in a remarkably dynamic, sulfide-rich, hypogenic cave in southern Mexico. In: White W.B. (Ed)., 15th International Congress of Speleology, Proceedings, 3: 15251530. 
Jackson J., 1997 - Glossary of Geology, American Geological Institute, 769 p.

Lyles J.T.M., 2009 - Two hundred kilometers in Lechuguilla Cave. In: White W.B. (Ed)., 15th International Congress of Speleology, Proceedings, 3: 1744-1749.

Plan L. \& De Waele J., 2011 - Folia in der Odelsteinhöhle, Steiermark. Erstnachweis im deutschsprachigen Raum (Folia in Odelstein Cave, Styria first description from the German-speaking realm). Die Höhle, 62: 54-57.
Queen M., 2009 - The Lost City: hot springs, mixing and a possible model for folia development. In: White W.B. (Ed)., 15th International Congress of Speleology, Proceedings, 3: 1650-1656.

Szabo B., Kolesar P., Riggs A., Winograd I. \& Ludwig K., 1994 - Paleoclimatic inferences from a 120,000yr calcite record of water-table fluctuation in Browns Room of Devils Hole, Nevada. Quaternary Research, 41: 59-69.

http://dx.doi.org/10.1006/qres.1994.1007 